\title{
A Study of the Attitudinal Resources in the Movie Reviews of The Wandering Earth-From the Perspective of Appraisal Theory
}

\author{
Yumin Gong \\ Shanxi Normal University, Linfen, China
}

\begin{abstract}
With the flourishing development of mass media, the industry of movie is now encountering a brand-new time. Meanwhile, as a special category of evaluation discourse which is closely related with movie, movie review is worthy of further study and appealing more and more attention. Movie reviewers tend to adopt a lot of appraisal resources especially attitudinal resources in their movie reviews, and it is of great value to study the appraisal resources in movie reviews under the framework of Appraisal Theory. Therefore, this thesis aims to analyze the attitudinal resource in movie reviews based on a corpus of 10 movie reviews of the Wandering Earth.
\end{abstract}

Index Terms — appraisal theory, attitudinal resource, movie review, the Wandering Earth

\section{INTRODUCTION}

\section{A. The Background of the Research}

A film review, as we know, is the analysis of and commentary on a movie including the director, the actors, the language and any other aspects. It aims to introduce the film and evaluate it, help the director improve his or her capacity and promote the development of movies. It has a great impact on the development of the film market. In the meantime, it can influence the understanding and appreciation of film viewers of the film. Nowadays, with the thriving of movie industry and the popularity of film reviews, people all over the world tend to check the film review before they decide whether or not to see a film. This is because it can provide them with some information about what the movie is about and if it is worth seeing. It is also seen as the driving force of the film industry today. The function of film review determines that this kind of discourse has abundant evaluative resources as well. In this sense, movie reviews are well worth exploring.

\section{B. Objectives of the Study}

As a matter of fact, film review, as a new type of discourse, has attracted many researchers' attention in recent years. There have been many studies on movie reviews from various perspectives. However, there are few studies about movie reviews that are from the perspective of Appraisal theory.

The appraisal framework, developed by Martin and White and their colleagues in the 1990s and 2000s, provides for analyses of meanings by which texts convey positive or negative assessments, by which the intensity or directness of such attitudinal utterances is strengthened or weakened and by which speakers/writers engage dialogistically with prior speakers or with potential respondents to the current proposition. These meaning making resources are grouped together as the "language of evaluation" on the grounds that they are all means by which the speaker's/writer's personal, evaluative involvement in the text is revealed as they adopt stances either toward phenomena (the entities, happenings, or states of affairs being construed by the text) or toward metaphenomena (propositions about these entities, happenings, and states of affairs) (White, 2015). Appraisal Theory, since it was put forward, has attracted much attention from researchers. It has been widely used to analyze literary criticism, art criticism historical discourse, and advertising discourse and so on. Many studies have been done about appraisal theory from the above-mentioned perspectives while movie reviews have rarely been studied from the perspective of Appraisal Theory. This thesis attempts to study film reviews with appraisal theory and focuses on the distribution of the attitude sub-systems in English film reviews.

\section{Organization of the Thesis}

The present paper includes six chapters.

Chapter one explains a brief background, the objectives and the significance of this study. And the organization will also be considered.

Chapter two is concerned with a brief review of the film review, and introduces the previous study of Appraisal Theory and film review at home and abroad.

Chapter three aims to explain the Appraisal Theory, which is the analytical framework of the present study.

Chapter four is the main body of the present study, in which the chosen film reviews are analyzed, especially 
attitudinal resources in details. The author analyzes the 10 English film reviews of The Wandering Earth. The author will also give some characteristics and reasons for such distribution.

Chapter five is the conclusion, in which the author will summarize major findings of the present study. Then the author will put out the limitation of the study and suggestions for further study.

\section{LITERATURE REVIEW}

In this chapter, the author will first discuss the overview of the film review. Then Appraisal theory will be presented and the application of Appraisal theory will be reviewed.

\section{A. An Overview of the Film Review}

1. The definition of the film review

The film review is a kind of discourse dealing with the evaluation of something about a movie. It is an introduction and evaluation of the movie or a study and explanation of the form and content of the movie (Hu, 2009: 176).

According to Wikipedia, a film review includes the plot summary and evaluation of a movie. It has an great impact on people's decision.

2. The function of the film review

The purpose of the film review is to attract the attentions of the readers to inform the readers of the information about the movie, to facilitate readers understanding of the movies theme and to convey the reviewer's opinions of the movie (Li, 1989)

The readers can get the whole outline of the movie after reading the film reviews. And this will give the audience the basis judgement on the worthwhile of the movie. Thus the function of film review is shown on. The Wandering Earth described the story happens in a disastrous future where the world government plans to physically move Earth away from destruction and start a centuries-long voyage to a new solar system. But humanity faces annihilation almost immediately, when scientists discover that Earth is on a obvious collision course with Jupiter.

\section{B. An Overview of Appraisal Theory}

1. The development of Appraisal Theory

Systemic Functional Linguistics (SFL), one of the major schools of linguistics, is created by Halliday in the 1960s and the early year of the 1970s. Language has three metafunctions: ideational function, interpersonal function and textual function. (Martin and White, 2008:7). In the year 1991 to 1994, Martin and White were engaged on the Write it Right literacy project, after that, they developed and established Appraisal theory. In the next year, Martin, White, Joan Rothery, Caroline Coffin and many other scholars, tried their efforts to the refinement and development of Appraisal theory. They applied appraisal analysis into analyzing several subject areas, which are narratives, literary criticisms, news reports and legal discourses (Martin \& White, 2008)

As has been introduced above, Appraisal Theory is not all by itself, but it is based on SFL, and it is the development and extension of interpersonal meanings in SFL.

2. The previous study of Appraisal Theory

Many scholars, at home and abroad, have made great efforts to the development of Appraisal Theory.

Abroad, Peter White (1988) applied Appraisal Theory to analyzing media discourse in newspapers and magazines. Especially, dialogic expansion and contraction of the engagement resources put into analysis.

Martin (2001) analyzed the rave review with Appraisal Theory, whose data were some reviews about pop music, books and videos from a website.

At home, the Appraisal Theory has been applied to many fields. Many scholars have paid great attention to the analysis of attitudinal resources under the Appraisal Theory.

Li Zhanzi (2001) wrote a paper entitled Broadening the Framework of interpersonal Meaning in Functional Grammar. The author explored the multiple means to realize interpersonal meaning. She suggested that people should analyze a discourse not only at the level of clause, but also at the level of the whole discourse. In her another paper, Appraisal Theory: Applications and Problems in Discourse Analysis, written in 2004, the author analyzed commercial, historical and autobiographical discourses with Appraisal Theory.

Wang Zhenhua (2001) wrote a paper named Appraisal Systems and Their Operation: A New Development in the Systemic Functional Linguistics. The author presented the background of Appraisal Theory, the theoretical framework and its operation.

So far, limited number of studies in China is devoted to investigating the evaluative resources in the film review in light of Appraisal Theory. Only a few scholars analyzed the film review under the attitudinal resources of Appraisal Theory. Therefore, the author decides to from the perspective of appraisal theory study attitudinal resources in the movie reviews of the Wandering Earth.

\section{DESCRIPTION OF THEORETICAL FRAMEWORK}

Attitude consists of these three sub-systems Attitude, Engagement and Graduation, and each of them can be further divided. In this part, the author will first introduce attitude and its three sub-systems on the whole, and then will give a 
specific explanation of the system of Attitude.

\section{A. Appraisal Theory}

Established by Halliday, SFL has become one of the most vital modern linguistic branches through nearly 40 years of expansion. It serves as a milestone in language study, and has been widely extended to be more and more comprehensive and systemic. However, SFL also has its deficiency that it pays less attention to the semantic meaning of evaluation in the discourse. As for SFL, ideational function, interpersonal function and textual function are three meta-functions of language. Among these three basic functions, the interpersonal function is only concerned with communication while neglecting affect. Seeing this deficiency, Martin and his colleagues put forward AT in the 1990s. They lay emphasis on emotion and communication, and argue that interpersonal meaning also contains writer's/speaker's attitudes towards people, things, or events. AT is a further development and extension of interpersonal meaning, ranging from the lexical-grammatical level to the discourse semantic level.

Evaluation is a fundamental function of language and plays an essential role in linguistic study. AT is constructed on the basis of evaluation, and mainly concerns with "the kinds of attitudes that are negotiated in a text, the strength of the feelings involved and the ways in which values are sourced and readers aligned"(Martin \& Rose, 2003: 22) In this definition, three sub-systems of AT are advocated, that are Attitude, Graduation and Engagement.

Within the framework of AT, Attitude is the core. It is used to source feelings and grade feelings, through which way Engagement and Graduation can be specified individually. Engagement is the source of Attitude dealing with the matter how Attitude resources are negotiated in a community. Graduation is the strength of attitude, modifying Attitude resources by means of force and focus.(Martin \&White, 2005).

Attitude can be used to describe people's feelings from the following three perspectives: emotional responses, judgments of behavior and evaluation of things. The system of Attitude can be divided into three regions of feelings, that are, "Affect", "Judgment" and "Appreciation" (Martin \&White, 2005: 35).

\section{B. Attitude}

According to Martin and White, Attitude indicates the resources that bear the writer/speaker's inter-subjective values or evaluation towards a specific person, an object or a category of social/natural phenomenon, either abstract or concrete.

As has been indicated, Attitude can be used to describe people's feelings from the following three perspectives: emotional responses, judgment of behavior as well as evaluation of objects. There are three sub-categories of Attitude that have been made clarified by this definition, namely, Affect, Judgment and Appreciation.

\section{Affect}

Affect is concerned with semantic resources for construing emotion. By means of Affect, the writers/speakers can indicate how they are manipulated to the object person incidents or situation in an emotional way. As has been indicated, affect is mainly deals with "registering negative and positive feelings: do we feel sad or happy, bored or interested, anxious or confident?" (Martin White, 2008: 42).

By way of classifying Affect, Martin and White (2008) actually drew on the following six elements. Here are the six relative factors. (1)Affect can either be negative or positive (e.g. the audiences hate the movie vs. the audiences love movie). (2)Affect can be construed as mental process/state or behavioral surge meaning that emotions may be depicted as internal mental activities or surge of paralinguistic manifestation (e.g. audiences felt sad about the scene vs. the audiences wept over the scene). (3) Affect can be constructed as reacting to or directed at some certain trigger or constructed as a general undirected mood for which a person may raise the question "Why are you feeling that way?(e.g. the audiences an pleased by the scene of reunion vs. the audiences are sad about the scene of reunion). The process might last up to a decade. We believe in local science fiction productions and we are willing to wait. (4)Affect is gradable. The emotional feelings can be graded towards "the higher valued end of intensity or towards the lower valued end, or somewhat in between, that is, they provide variables of high, low and median values. (5)Affect can be generally divided into realis and irrealis Affect. (6)Realis affect can be mainly divided into three subsets: un/happiness, in/security, and dis/satisfaction.

2. Judgment

Judgment refers to the semantic resources that construct people's attitudes towards others' behavior typically by reference to some series of social norms, such as conventions, laws, and systems of value, etc. Generally speaking, judgment can be classified into those oriented to "social esteem" as well as those dealing with "social sanction".

As Martin and White (2008) have pointed out that "judgement resources are aimed at normality (how unusual someone is), capacity (how capable they are) as well as tenacity (how resolute they are); Judgement resources of sanction are aimed at "veracity" (how truthful someone is) and "propriety" (how ethical someone is). If the variables are loaded with too much negative social esteem, they will be reduced in the esteem of their community. On the contrary, if the variables are loaded with much positive social esteem, they will be improved in the esteem of their community. The jump into sci-fi reflects Chinese filmmakers' growing budgets and confidence to deal with topics previously monopolized by Hollywood. That is to say, Judgment of social esteem has neither moral nor legal implication. In contrast with social esteem resources, Judgment of social sanction deals with the theme related with legality and morality (White, 1998: 35). If people plus too much negative social sanction in their evaluation, they would encounter 
the hazards of religious or legal punishment. When it comes to social sanction, it can be further divided into two sub-systems, veracity and propriety. The system of veracity is related with the question of how truthful someone is, while the system of propriety concerns how ethical someone is. The country's first blockbuster set in space, "The Wandering Earth," opens Tuesday amid grandiose expectations that it will symbolize the dawning of a new era in Chinese filmmaking.

\section{Appreciation}

Appreciation variables are the semantic resources for positive and negative evaluations of objects, processes, states of affairs and natural phenomena. With Appreciation, Martin and White tum to meanings construing assessments of things, that is, Appreciation is thing-oriented. This element distinguishes Appreciation from Affect and Judgment.

According to Martin and White (2008:56), Appreciation can be further stratified into the following three systems, namely, reaction, composition and valuation. Reaction includes two aspects: impact and quality. Impact is adopted to assess how the things grasp people's attention; quality is utilized to evaluate how the things please people. Composition is divided into balance and complexity. Balance is the appropriative principle through which the balance of "things" is evaluated; complexity is the approve principle adopted to analyze how complicated the "things" are. Valuation is meant to appreciate the value of the things, including how innovative, authentic and timely they are. "China's first domestic sci-fi blockbuster The Wandering Earth has dominated the box office and online film review sites during the Chinese New Year holiday. It is one in a series of ambitious, big-budget films dealing with a genre that has been beyond the reach of most filmmakers here, technically and financially. The Wandering Earth has a never-seen-before element in its plot. The Earth, as we know it, is being lifted into another solar system. Whoa! The film looks highly stylized, at par with Hollywood standards, even beyond, at times. Both The Wandering Earth and Crazy Alien are adapted from works by Liu Cixin, the writer who has led a revival in science fiction here, becoming the first Chinese champion of the Hugo Award for the genre in 2015. Li's novels are sprawling epics and deeply researched. That makes them believable fantasies about humanity's encounters with a risky universe." Like Hollywood space movies where Americans are depicted as the only ones capable of saving humanity, here Chinese astronauts are the single adventurers among the global space community determined to finish the hard task of fending off the apocalypse. Chinese cultural virtues of duty, humility, self-sacrifice, and loyalty, both to family and society as a whole.

\section{DATA AND ANALYsis of AtTITUDinal RESOURCES}

In this chapter, the author will explain the source of the corpus and analyze attitudinal resources in the Movie Reviews of the Wandering Earth.

\section{A. The Corpus}

The present study collects the data from English mainstream newspaper and magazine websites and Chinese authoritative newspaper and magazine websites. In order to be more objective, the author will select 8 English film reviews from websites of famous English newspapers, magazines and forum which are The New York Times, South China Morning Post, Forbes, The Verge, Financial Times, The Guardian, Flicks.com, News 18. These kinds of newspapers are all influential, authoritative, and widely read by native people. And the magazine and forum presents the masses' ideas towards the movie. Then the author will select another 2 Chinese film reviews from official newspapers. This can make the collected data more objective and comprehensive. All these qualify film reviews can be the target data of the present study.

\section{B. Analysis of Attitudinal Resources in Film Reviews of the Wandering Earth}

TABLE 3.1

\begin{tabular}{|c|c|c|c|c|c|c|}
\hline Media & Affect & Frequency & Judgement & Frequency & Appreciation & Frequency \\
\hline People's Daily & 12 & $24 \%$ & 16 & $32 \%$ & 22 & $44 \%$ \\
\hline Xinhua's Daily & 10 & $19.61 \%$ & 15 & $29.41 \%$ & 26 & $50.98 \%$ \\
\hline South China Morning Post & 15 & $23.81 \%$ & 20 & $31.75 \%$ & 28 & $44.44 \%$ \\
\hline The New York Times & 16 & $23.53 \%$ & 22 & $32.35 \%$ & 30 & $44.12 \%$ \\
\hline Forbes & 18 & $24.66 \%$ & 25 & $34.25 \%$ & 30 & $41.10 \%$ \\
\hline The Verge & 15 & $20.27 \%$ & 26 & $35.14 \%$ & 33 & 44.59 \\
\hline Flicks.com & 10 & $19.23 \%$ & 18 & $34.62 \%$ & 24 & $46.15 \%$ \\
\hline News 18.com & 9 & $20 \%$ & 15 & $33.33 \%$ & 21 & $46.67 \%$ \\
\hline
\end{tabular}

As can be seen from table 3.1, among the 10 Chinese and foreign media reviews on The Wandering Earth, the most frequent one is appreciation, which accounts for the attitude system. The overall mean was 44.64\%. Judgment appears less frequently, accounting for the attitude system. The overall mean was $33.23 \%$; Affect appears least frequently, accounting for attitude. The system average was $21.9 \%$. The analysis of both English and Chinese film reviews of The Wandering Earth has been discussed.

And the statistics has also been figured out. The author will summarize this chapter in the following part:

Firstly, in terms of Attitude system, the respective distribution of Affect, Judgement, Appreciation resources in both 
English and Chinese film reviews of The Wandering Earth, the proportion of Affect resources accounts for the smallest quantity of the three systems of Attitude values, and the proportion of Appreciation resources is the largest, followed by Judgement resources. And the explicit affect, explicit judgement and explicit appreciation take the majority of each value. The reason for these features of appraisal resources is that the writers want to give the readers an impression of objectivity, so they try to avoid employing affective or emotional resources when writing film reviews.

Secondly, after analyzing the features of Attitude resources in both English and Chinese film reviews of The Wandering Earth, the author has found out some features of both English and Chinese film reviews. The conclusion is as follows: English and Chinese film reviews both are a special kind of discourse. They tend to be more subjective, but due to different cultural backgrounds, Chinese film review is more subjective than English film review. Although the writers try to avoid emotional resources affecting on the readers, they still use lexical words of judgement and appreciation, which belong to writers' subjective opinions. We can also discover that the film directors and actors are often judged from the perspective of capacity, and the people described in the films are often evaluated in normality in English film reviews For Chinese film review, the reviewers judge film directors and actors from the perspective of capacity and persons are often evaluated from the perspective of tenacity. As for the lowest subjective resources, appreciation values, the reaction and valuation appreciation take the majority quantity of the whole appreciation values in both English and Chinese film reviews of The Wandering Earth.

\section{CONCLUSION}

The current study explores the evaluative features, specially focusing on the attitudinal resources in both English and Chinese film reviews of the movie The Wandering Earth. The film review as a kind of genre is seldom analyzed by linguistic scholars under Appraisal Theory. After careful analysis of the data, the distribution of attitudinal resources can be presented. And the author analyzed the reasons for such occurrence. The thesis is concluded with a contrastive analysis of the realization of interpersonal meaning between English and Chinese film reviews.

After a careful analysis of film reviews of The Wandering Earth, the author has arrived at some conclusions, and the major findings are as follows:

Firstly. English film review as a special kind of discourse has two characteristics. For one, English film review is a bit subjective. Since the reviewers use a lot of words of judgement and appreciation, it is considered as objective. The other feature is that the film directors and actors are often judged from the perspective of capacity and persons described in the movie are often evaluated from the perspective of propriety.

Secondly the contrastive analysis of attitudinal values between English and Chinese film reviews of The Wandering Earth shows that attitudinal resources are employed to fulfill the interpersonal function. When the reviewers write the film reviews, affect values are used to convey the writers emotional response to the movie, which would share their own feelings with the readers. Therefore, after reading the film reviews, the reviewers can get along with the readers through the reviews.

Thirdly, the author finds that the affect resources in film reviews of The Wandering Earth take account for the smallest proportion, judgement and appreciation resources are shown on be the dominant Attitudes among 40 film reviews. The reason for this linguistic feature in film reviews of The Wandering Earth is that the authors of both English and Chinese film reviews pay more attention to the human behavior and objects than people's emotional feelings. They want to give the reader an impression of objectivity, in order to make the reviews persuasive and convincing, thus giving the readers worthwhile information out the movie. In other words, the reviewers focus more on the truthfulness of this historical story. They try to use the objective words to make sure the readers.

\section{REFERENCES}

[1] Hu, Z., Y. Zhu, D. Zhang \& Z. Li. (2017). Introduction to Systemic Functional Linguistics. Beijing: Peking University Press.

[2] Ji, L. (2008). Study on the Actuality, Characteristics and Developing Situation of Internet Film Review in China. Dissertation, Shanghai Jiao Tong University.

[3] Li, N. (2009). "Popular Film" (1979-1989). Dissertation, Southwest University.

[4] Li, R. (2005). The Attitudinal Meanings of English Column Texts-From the Perspective of Appraisal Theory. Shandong Foreign Language Teaching Journal, 4, 30-33.

[5] Martin, J. R. \& P. R. R. White. (2008). The Language of Evaluation: Appraisal in English. Beijing: Foreign Language Teaching and Research Press.

[6] Martin \& Rose. (2003). Working with Discourse: Meaning Beyond the Clause. London: Continuum.

[7] Peter R. R. White. (2015). Appraisal Theory. University of New South Wales, Australia.

[8] Wang, Z. (2001). Appraisal Systems and Their Operation: A New Development in the Systemic Functional Linguistics. Journal of Foreign Languages, 6, 13-20.

[9] Wang, Z.\& Y. Ma. (2007). Appraisal Theory: Charm and Dilemma. Foreign Language Education, 6, 19-23.

[10] Wang, Z. (2009). A Framework for TEXT Semantic Study: One Paradigm, Two Strands, Three Meta-functions, Four Meta-semantics and Five Aspects. Foreign Languages in China, 6, 26-38.

[11] Xu, Y. (2013). Review and Prospect of Appraisal Theory in China. Foreign Language Education, 3,11-15.

[12] Yang, X. (2003). Evaluative Device in Text. Foreign Languages and Their Teaching, 1, 11-14.

[13] Zhu, Y. \& Z. Wang. (2013). Research on Martin's Academic Thought. Beijing: Peking University Press. 
Yumin Gong was born in Taiyuan, China in 1994. She received her bachelor degree in translation from Tianjin University of Commerce Boustead College, China in 2017.

She is currently a master degree candidate in the School of Foreign Language, Shanxi Normal University, Linfen, China. Her research interests include pragmatics and translation. 